\title{
FONTES DE FÓSFORO APLICADAS NA CULTURA DO MELÃO VIA ÁGUA DE IRRIGAÇÃo
}

\author{
Luiza Teixeira de Lima Brito ${ }^{1}$, José Monteiro Soares ${ }^{2}$, Clementino Marcos Batista de Faria ${ }^{3}$ \& \\ Nivaldo Duarte Costa ${ }^{3}$
}

\begin{abstract}
RESUMO
Este estudo teve por objetivo avaliar o efeito de fontes de fósforo aplicadas via água de irrigação e, de modo convencional, na cultura do melão (Cucumis melo L.), híbrido AF-682, em um Latossolo Vermelho-Amarelo. As fontes analisadas foram superfosfato simples, fosfato monoamônico (MAP) e ácido fosfórico, aplicadas até 30 e 42 dias após o plantio. Todos os tratamentos receberam a mesma dosagem $\left(120 \mathrm{~kg} \mathrm{ha}^{-1} \mathrm{de}_{2} \mathrm{O}_{5}\right)$, conforme recomendado pela análise do solo. O delineamento experimental foi de blocos casualizados, com quatro repetições. Constatou-se que as maiores produtividades de frutos comerciais foram obtidas com ácido fosfórico $\left(32,20\right.$ e 28,90 tha $\left.{ }^{-1}\right)$ aplicado via água de irrigação até 42 e 30 dias após a germinação, respectivamente, não diferindo das produtividades com o MAP aplicado via água de irrigação até 42 dias após a germinação $\left(27,95 \mathrm{t} \mathrm{ha}^{-1}\right)$ e pelo modo convencional $\left(26,92 \mathrm{t} \mathrm{ha}^{-1}\right)$. Verificou-se que as fontes de fósforo e os modos de aplicação não influenciaram no peso médio dos frutos $(1,43 \mathrm{~kg})$, sendo que $65 \%$ dos frutos obtidos se enquadraram nos tipos 8 a 10 ; entretanto, observou-se diferença significativa para o teor de sólidos solúveis totais (SST) nos frutos, por ocasião da colheita, com o maior valor obtido com o ácido fosfórico $\left(12,53^{\circ}\right.$ brix $)$.
\end{abstract}

Palavras-chave: Cucumis melo, fertirrigação, produtividade, qualidade de fruto

\section{SOURCES OF PHOSPHORUS APPLIED THROUGH FERTIGATION IN MUSKMELON}

\begin{abstract}
This study was carried out with the objective of evaluating the effect of three phosphorus sources applied conventionally and through trickle irrigation on melon crop (Cucumis melo L.), hybrid AF-682. The sources of phosphorus were simple superphosphate, monoammonium phosphate (MAP) and phosphoric acid applied up to 30 and 42 days after germination through trickle irrigation and conventionally. The experiment was conducted in a completely randomized block design, with four replications. All the treatments had the same amount of phosphorus $\left(120 \mathrm{~kg} \mathrm{ha}^{-1}\right.$ of $\left.\mathrm{P}_{2} \mathrm{O}_{5}\right)$ according to soil analysis. The highest commercial fruit yields were obtained with phosphoric acid applied through trickle irrigation up to 30 and 42 days after germination (28.90 and $32.20 \mathrm{t} \mathrm{ha}^{-1}$, respectively), not differing from MAP applied through trickle irrigation up to 42 days after germination $\left(27.95 \mathrm{tha}^{-1}\right)$. The sources of phosphorus and modes of application did not influence the mean weight of fruits $(1.43 \mathrm{~kg})$, $65 \%$ of fruits being of type 8 to 10 ; however differences were observed in the soluble solids content at harvest time, highest content (brix $12.53^{\circ}$ ) was obtained in phosphoric acid treatment.
\end{abstract}

Key words: Cucumis melo, fertigation, yield, fruit quality

\footnotetext{
Recebido em 19/08/1999, Protocolo 095/99

${ }^{1}$ Eng. Agrícola, M. Sc., Embrapa - Semi-Árido, CP 23, CEP 56300 - 000, Petrolina, PE. Doutorando em Recursos Naturais, UFPB-CCT, Campina Grande, PB. Fone: (0xx81) 862 1711, Fax: (0xx81) 862 1744. E-mail: luizatlb@ cpatsa.embrapa.br

${ }^{2}$ Eng. Agro. M.Sc., Embrapa-Semi-Árido. Doutorando em Recursos Naturais, UFPB/CCT

${ }^{3}$ Eng. Agro. M.Sc., Embrapa-Semi-Árido
} 


\section{INTRODUÇÃO}

A agricultura irrigada representa papel preponderante para o desenvolvimento da região Nordeste brasileira, observando-se que nas últimas décadas esta região passou da condição de importadora de hortifrutícolas para exportadora, tendo na cultura do meloeiro expressiva representatividade na pauta de exportação de frutos.

Nesta região, as áreas produtoras de melão concentram-se principalmente nos Estados do Rio Grande do Norte, Ceará, Bahia, Pernambuco e Paraíba, os quais têm respondido, nos últimos anos, por aproximadamente $90 \%$ da produção nacional, cuja receita estimada em 1996 foi de R \$ 92 milhões, considerandose os mercados interno e externo (Dias et al., 1998).

Entre 1980 e 1996, a área cultivada com a cultura do melão no Brasil teve aumento de $116 \%$, aproximadamente, enquanto o incremento na produção foi de $260 \%$ (Dias et al., 1998). Este acréscimo se deve à melhoria em seus sistemas de produção, com consequientes aumentos na eficiência de uso de insumos básicos utilizados, em que a irrigação e a fertilização são imprescindíveis.

O uso da fertilização combinada com a água de irrigação, conhecida como fertirrigação, tem assumido papel preponderante, por apresentar maior eficácia no sistema de produção e proporcionar melhor distribuição dos nutrientes no volume de solo explorado pelo sistema radicular durante o ciclo das culturas (Souza, 1993), além de promover o parcelamento das aplicações dos nutrientes que, associadas às irrigações diárias, por gotejamento, favorecem maior eficiência de uso de nutrientes e, conseqüentemente, menor perda por lixiviação; no entanto, esta prática tem sido utilizada, algumas vezes, de forma inadequada, pela falta de definição de parâmetros relacionados ao período e à freqüência de aplicação, doses e fontes de nutrientes para as culturas de maior expressão econômica.

A partir de meados da década de 80, o Centro de Pesquisa Agropecuária do Trópico Semi-Árido (CPATSA) da Embrapa, iniciou estudos com fertirrigação nas culturas de melão, mangueira e videira. Atualmente, muitos parâmetros relacionados à fertirrigação na cultura do melão estão definidos (Pinto et al., 1993, 1994, 1996).

A aplicação de fertilizantes em pequenas doses reduz sua lixiviação, evitando a contaminação do lençol freático e de reservatórios de água superficiais e subterrâneos. A fertirrigação atende às necessidades nutricionais das plantas ao longo de suas distintas fases fenológicas, sendo perfeitamente adaptável aos diferentes sistemas de irrigação; contudo, a irrigação por gotejamento e por microaspersão oferece maior flexibilidade à fertirrigação, seguida pela aspersão (Goldberg \& Shmueli, 1970).

Em razão da baixa solubilidade, tradicionalmente o fósforo é aplicado em fundação, antes do plantio. Com a introdução, no mercado, de nutrientes fosfatados solúveis em água como, por exemplo, o fosfato monoamônico (MAP) e o ácido fosfórico, partiu-se para o estudo da sua aplicação diretamente na água de irrigação. Brito et al. (1996) avaliaram o efeito de duas fontes de fósforo, superfosfato simples e MAP aplicadas convencionalmente e via água de irrigação na cultura do melão, e não observaram diferenças significativas entre as fontes, quando aplicadas de modo convencional e/ou via água de irrigação por 30 e 42 dias após o plantio.
Este trabalho foi desenvolvido com o objetivo de se avaliar o efeito de três fontes de fósforo, superfosfato simples, MAP e ácido fosfórico, aplicadas de modo convencional e via água de irrigação, na produtividade e na qualidade dos frutos de melão.

\section{MATERIAL E MÉTODOS}

No Campo Experimental de Bebedouro, pertencente à Embrapa, em Petrolina, PE, realizaram-se estudos com a cultura do melão (Cucumis melo L), híbrido AF-682. O solo utilizado é da classe Latossolo Vermelho-Amarelo, com profundidade média de 1,5 m, baixa capacidade de troca de cátions e baixo teor de matéria orgânica (Pereira \& Souza, 1967). As características fisico-hídricas da camada arável do solo, determinadas por Choudhury \& Millar (1981) mostram que se trata de um solo de textura arenosa, com baixa capacidade de retenção de umidade (Tabela 1).

Tabela 1. Características físico-hídricas do solo da área experimental

\begin{tabular}{lcc}
\hline \multicolumn{1}{c}{ Características Fisico-hídricas } & \multicolumn{2}{c}{ Profundidade do Solo $(\mathrm{cm})$} \\
\cline { 2 - 3 } & $0-30$ & $30-60$ \\
\hline Areia grossa $\left(\mathrm{g} \mathrm{kg}^{-1}\right)$ & 40 & 50 \\
Areia fina $\left(\mathrm{g} \mathrm{kg}^{-1}\right)$ & 870 & 820 \\
Silte $\left(\mathrm{g} \mathrm{kg}^{-1}\right)$ & 40 & 50 \\
Argila $\left(\mathrm{g} \mathrm{kg}^{-1}\right)$ & 50 & 80 \\
Classificação textural & Areia & Areia franca \\
Densidade aparente $\left(\mathrm{kg} \mathrm{dm}^{-3}\right)$ & 1,62 & 1,68 \\
Densidade real $\left(\mathrm{kg} \mathrm{dm}^{-3}\right)$ & 2,72 & 2,74 \\
Porosidade total $(\%)$ & 40,4 & 38,7 \\
Capacidade de campo - 33 kPa $\left(\mathrm{g} \mathrm{kg}^{-1}\right)$ & 89,4 & 90,0 \\
Retenção de água - $1500 \mathrm{kPa}\left(\mathrm{g} \mathrm{kg}^{-1}\right)$ & 18,4 & 25,2 \\
\hline Fonte: Choudhury \& Millar $(1981)$ & &
\end{tabular}

Fonte: Choudhury \& Millar (1981)

O experimento consistiu de seis tratamentos: $\mathrm{T}_{1}$ - superfosfato simples; $\mathrm{T}_{2}$ - MAP (fosfato monoamônico), ambos aplicados pelo método convencional (em fundação); $\mathrm{T}_{3}$ - MAP, aplicado

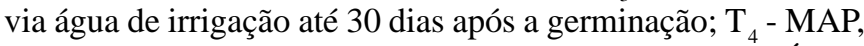
via água de irrigação até 42 dias após a germinação; $\mathrm{T}_{5}$ - Ácido fosfórico aplicado via água de irrigação até 30 dias após a germinação; e T 6 - Ácido fosfórico aplicado via água de irrigação até 42 dias após a germinação. Todos os tratamentos receberam a mesma dosagem $\left(120 \mathrm{~kg} \mathrm{ha}^{-1} \mathrm{de}_{2} \mathrm{O}_{5}\right)$ conforme recomendado pela análise do solo. O delineamento experimental foi de blocos casualizados, com quatro repetições. A área total da unidade experimental foi de $40 \mathrm{~m}^{2}$ e a área útil de $34,2 \mathrm{~m}^{2}$.

O espaçamento utilizado foi de $1,8 \mathrm{~m}$ entre linhas por $0,5 \mathrm{~m}$ entre plantas, com uma planta por cova, utilizando-se o sistema de irrigação por gotejamento em linha, com gotejadores espaçados $1 \mathrm{~m}$, vazão de $4 \mathrm{~L} \mathrm{~h}^{-1}$ e pressão de $0,10 \mathrm{MPa}$. As irrigações foram feitas diariamente, com base na evaporação da água do tanque classe A e no coeficiente de cultura $(\mathrm{kc})$. Procurou-se minimizar as perdas de água por percolação abaixo da profundidade efetiva das raízes, através do monitoramento da umidade do solo, utilizando-se tensiômetros de mercúrio instalados a 0,15 e $0,30 \mathrm{~m}$ de profundidade.

Todos os tratamentos receberam adubação de $90 \mathrm{~kg} \mathrm{ha}^{-1} \mathrm{de}$ $\mathrm{K}_{2} \mathrm{O}$ e $80 \mathrm{~kg} \mathrm{ha}^{-1}$ de $\mathrm{N}$, sendo considerada a quantidade de $\mathrm{N}$ aplicado via MAP. O nitrogênio e o potássio tiveram, como 
fontes, a uréia e o cloreto de potássio, respectivamente, e foram aplicados diariamente via fertirrigação até 42 dias após a germinação, utilizando-se um injetor hidráulico de fertilizantes.

Foram realizadas três colheitas: aos 62, 70 e 78 dias após o plantio. Além da produtividade, avaliaram-se o peso médio e o brix dos frutos e se efetuou a classificação dos frutos por tipo que, segundo Gorgatti Neto et al. (1994), o tamanho do fruto é uma característica determinante para sua comercialização, tendo aceitação frutos com até dois quilos.

\section{RESULTADOS E DISCUSSÃO}

A análise de variância mostrou que houve diferença significativa em nível de 5\% de probabilidade pelo teste de Tukey (Tabela 2), para produtividades comercial e total de frutos, teores de sólidos solúveis totais (SST) e a relação brix/acidez (SST/ ATT). Pode-se constatar que a maior produtividade comercial de frutos $\left(32,20 \mathrm{t} \mathrm{ha}^{-1}\right)$ foi obtida com o ácido fosfórico aplicado via água de irrigação, até 42 dias após a germinação, a qual não diferiu do tratamento em que o ácido fosfórico foi aplicado até 30 dias após a germinação $\left(28,90 \mathrm{tha}^{-1}\right)$ como, também, do MAP aplicado até 42 dias $\left(27,95 \mathrm{t} \mathrm{ha}^{-1}\right)$ e pelo modo convencional $\left(26,92 \mathrm{t} \mathrm{ha}^{-1}\right)$. Pode-se constatar, também, que a menor produtividade $\left(25,33 \mathrm{tha}^{-1}\right)$ foi obtida com o MAP aplicado via água de irrigação até 30 dias após a germinação (Tabela 2). Brito et al. (1996) analisando as fontes de fósforo correspondentes ao superfosfato simples e MAP aplicados convencionalmente, e MAP aplicado até 30 dias após a germinação, obtiveram produtividades comerciais de frutos de melão de 25,96, 27,42 e $23,53 \mathrm{t} \mathrm{ha}^{-1}$, respectivamente. Como se observa, em ambos os estudos a menor produtividade comercial foi obtida com o MAP aplicado até 30 dias após a germinação.

Apesar de não terem sido constatadas diferenças significativas entre os tratamentos em que se aplicou o ácido fosfórico $\left(32,20 \mathrm{t} \mathrm{ha}^{-1}\right)$ e o MAP convencionalmente $(26,92$ $\mathrm{t} \mathrm{ha}^{-1}$ ), observou-se diferença de produtividade de 5,28 $\mathrm{t} \mathrm{ha}^{-1}$, o que pode ser bastante significativo quanto aos aspectos econômicos, uma vez que esta diferença representa $35,20 \%$ da produtividade média obtida na região, a qual é da ordem de 15,0 tha $^{-1}$.

Segundo Costa et al. (1986) a quantidade de fósforo aplicada no plantio satisfaz, geralmente, as necessidades da cultura, pois as plantas necessitam de fósforo, principalmente no início do seu desenvolvimento vegetativo. Para Prabhakar et al. (1985) a influência do fósforo sobre os frutos do melão tem efeito indireto, devido à sua importância na fase reprodutiva da planta. Esses autores observaram aumento no número de frutos com a aplicação desse elemento. Resultados semelhantes foram encontrados por Faria et al. (1994) que, além do aumento no número de frutos, observaram também aumento no seu peso médio.

Quando se considerou o peso médio de frutos, não se observaram, porém, diferenças significativas entre as fontes e modos de aplicação, tendo o peso dos frutos oscilado entre 1,39 e $1,48 \mathrm{~kg} \mathrm{fruto}^{-1}$ (Tabela 2), sendo esta uma característica de relevante importância para se definir o mercado consumidor. Segundo Lopes (1990), o mercado internacional prefere frutos pequenos e doces. Dusi (1992) afirma que o peso ideal do fruto para este mercado está entre 1,0 e 1,3 kg fruto ${ }^{-1}$, mas Gorgatti Neto et al. (1994) informam que há mercado para frutos com peso de até $2,0 \mathrm{~kg}$. Os resultados encontrados no presente trabalho atendem plenamente a essas exigências, uma vez que 0 peso médio do fruto foi de $1,43 \mathrm{~kg}$.

Observaram-se diferenças significativas entre as fontes de fósforo analisadas para o teor de sólidos solúveis nos frutos por ocasião da colheita, sendo o maior valor obtido com o ácido fosfórico aplicado até 42 dias após a germinação $\left(12,53^{\circ}\right.$ brix $)$, o qual diferiu das fontes do superfosfato simples, aplicado convencionalmente $\left(10,92^{\circ}\right.$ brix $)$ e do MAP, aplicado até 30 dias após a germinação $\left(10,60^{\circ}\right.$ brix). Para a acidez total titulável (ATT) não foram observadas diferenças significativas; no entanto, foram observadas diferenças na relação brix/acidez, sendo o maior valor obtido com o ácido fosfórico aplicado via água de irrigação até 30 dias após a germinação (Tabela 2).

Srinivas \& Prabhakar (1984) encontraram respostas significativas na influência do fósforo sobre o teor de sólidos solúveis totais (SST) dos frutos de melão. Suarez \& Ramirez (1985) consideram que as exigências do teor de sólidos solúveis para o mercado de exportação variam entre 9 e $10^{\circ}$ brix. Gorgatti Neto et al. (1994) classificam como não comercializáveis frutos com SST inferiores a $9^{\circ}$ brix; de $9^{\circ}$ a $12^{\circ}$ brix como comercializáveis e, acima de $12^{\circ}$ brix, são considerados melões extras, inseridos nesta classificação os frutos obtidos nos tratamentos em que se utilizou o ácido fosfórico (12,53 ${ }^{\circ}$ brix). Neste contexto, os teores de sólidos solúveis dos frutos também atendem às exigências dos mercados interno e externo.

Analisando-se a classificação dos frutos por tipo, pode-se constatar que, em termos médios, $65 \%$ dos frutos estão enquadrados nos tipos 8 a 10, $15 \%$ nos tipos 5 a 7 e $20 \%$ nos tipos 12 a 14 (Tabela 3). Sabe-se que a preferência do mercado externo é por frutos dos tipos 8 e 10, enquanto a do mercado

Tabela 2. Médias* de produtividades comercial e total, peso médio do fruto e parâmetros qualitativos da cultura do melão fertirrigado, sob diferentes fontes de fósforo - CEB-98

\begin{tabular}{|c|c|c|c|c|c|c|c|}
\hline \multicolumn{2}{|c|}{ Tratamentos } & \multicolumn{2}{|c|}{ Produtividades $(\mathrm{t} / \mathrm{h})$} & \multirow{2}{*}{$\begin{array}{c}\text { Peso } \\
\text { Médio } \\
\text { Fruto }(\mathrm{kg})\end{array}$} & \multirow{2}{*}{$\begin{array}{c}\text { Sólidos } \\
\text { Solúveis } \\
\text { Totais }\left({ }^{\circ} \text { Brix }\right)\end{array}$} & \multirow{2}{*}{$\begin{array}{c}\text { Acidez Total } \\
\text { Titulável (ATT) }\end{array}$} & \multirow{2}{*}{$\begin{array}{l}\text { SST/ } \\
\text { ATT }\end{array}$} \\
\hline Fontes de Fertilizante & $\begin{array}{l}\text { Método de } \\
\text { Aplicação }\end{array}$ & Comercial & Total & & & & \\
\hline Ácido Fosfórico & Via água-42 dias & $32,20 \mathrm{a}$ & $32,42 \mathrm{a}$ & $1,45 \mathrm{a}$ & $12,53 \mathrm{a}$ & $0,23 \mathrm{a}$ & $50,99 \mathrm{~b}$ \\
\hline MAP & Via água-42 dias & $27,95 \mathrm{ab}$ & $28,69 \mathrm{ab}$ & $1,44 \mathrm{a}$ & $11,32 \mathrm{ab}$ & $0,20 \mathrm{a}$ & $58,61 \mathrm{ab}$ \\
\hline MAP & Convencional & $26,92 \mathrm{ab}$ & $27,24 \mathrm{ab}$ & $1,48 \mathrm{a}$ & $11,35 \mathrm{ab}$ & $0,23 \mathrm{a}$ & $50,73 \mathrm{~b}$ \\
\hline Superfosfato Simples & Convencional & $25,86 \mathrm{~b}$ & $26,34 \mathrm{ab}$ & $1,39 \mathrm{a}$ & $10,92 \mathrm{~b}$ & $0,23 \mathrm{a}$ & $48,96 \mathrm{~b}$ \\
\hline
\end{tabular}


Tabela 3. Classificação dos frutos de melão quanto ao tipo, em função das fontes e períodos de aplicação do fertilizante fosfatado - CEB-1998

\begin{tabular}{|c|c|c|c|c|c|c|c|c|c|}
\hline \multicolumn{2}{|c|}{ Tratamentos } & \multicolumn{8}{|c|}{ Tipo de Frutos } \\
\hline \multirow{2}{*}{$\begin{array}{c}\text { Fontes de } \\
\text { Fertilizantes }\end{array}$} & \multirow{2}{*}{$\begin{array}{l}\text { Método de } \\
\text { Aplicação }\end{array}$} & 5 & 6 & 7 & 8 & 9 & 10 & 12 & 14 \\
\hline & & \multicolumn{8}{|c|}{$(\%)$} \\
\hline Ácido Fosfórico & Via água-30 dias & 6,0 & 17,8 & 8,9 & 23,5 & 13,0 & 18,2 & 7,3 & 5,3 \\
\hline MAP & Via água-42 dias & 0,4 & 5,2 & 2,2 & 19,3 & 20,1 & 19,3 & 19,3 & 14,1 \\
\hline MAP & Convencional & 2,5 & 5,4 & 6,1 & 21,1 & 17,6 & 21,9 & 14,3 & 11,1 \\
\hline
\end{tabular}

interno é por frutos dos tipos 6 e 8 (Pinto et al., 1996). Portanto, verifica-se que o tamanho dos frutos obtidos satisfaz às exigências de ambos os mercados consumidores.

\section{CONCLUSÕES}

1. As produtividades de frutos comerciais $\left(32,20 \mathrm{e} 28,90 \mathrm{tha}^{-1}\right)$ obtidas com o ácido fosfórico até 42 e 30 dias após a germinação, respectivamente, não diferiram das produtividades obtidas com o MAP aplicado via água de irrigação até 42 dias após a germinação $\left(27,95 \mathrm{t} \mathrm{ha}^{-1}\right)$ e convencionalmente $\left(26,92 \mathrm{t} \mathrm{ha}^{-1}\right)$.

2. As fontes de fósforo e os modos de aplicação não influenciaram no peso médio dos frutos, tendo as variações oscilado em torno de $1,43 \mathrm{~kg}$.

3. Observou-se que o ácido fosfórico proporcionou maior teor de sólidos solúveis totais $\left(12,53^{\circ}\right.$ brix $)$ nos frutos por ocasião da colheita.

4. Atendendo às exigências dos mercados, $65 \%$ dos frutos comerciais estão enquadrados nos tipos 8 a 10.

\section{REFERÊNCIAS BIBLIOGRÁFICAS}

BRITO, L.T. de L.; COSTA, N.D.; SOARES J.M.; FARIA, C.M.B. Fontes de fósforo aplicadas via fertirrigação na cultura do melão. In: REUNIÃO BRASILEIRA DE FERTILIDADE DO SOLO ENUTRIÇÃO DE PLANTAS, 22, 1996, Manaus, AM, Resumos... Manaus: SBCS/UA/EMBRAPA/INPE, 1996. p.194.

CHOUDHURY,E.N.; MILLAR, A.A. Características físico-hídricas de três Latossolos irrigados do Projeto Bebedouro. In: EMBRAPA. Centro de Pesquisa Agropecuária do Trópico Semi-Árido (Petrolina, PE). Pesquisa em irrigação no trópico semi-árido: Solo, água, planta. Petrolina, PE: Embrapa-CPATSA, 1981. p.1-24. Boletim de Pesquisa, 4.

COSTA, E.F. da; FRANÇA, G.E. de; ALVES, V.M.C. Aplicação de fertilizantes via água de irrigação. Informe Agropecuário, Belo Horizonte, v.12, n.139, p.63-69, 1986.

DIAS, R. de C.S.; COSTA, N.D.; CERDAN, C.; SILVA, P.C.G. da; QUEIROZ, M.A. de; OLIVEIRA, F.Z. de; LEITE, L.A. de S.; PESSOA, P.F.A de P.; TERAO, D. A cadeia produtiva do melão no Nordeste. IN: CASTRO, A.M.G. de; LIMA, S.M.V.; GOEDERT, W.J.; FREITAS FILHO, A. de; VASCONCELOS, J.R.P. (ed.) Cadeias produtivas e sistemas naturais: Prospecção tecnológica. Brasília:EMBRAPA.SPI/EMBRAPA-DPD, 1998. Cap. 17, p.441-494.

DUSI, A.N. Melão para exportação: Aspectos técnicos da produção. Brasília: DENACOOP, 1992. 38p. Série Publicações Técnicas, 1 .
FARIA, C.M.B. de; PEREIRA, J.R.; POSSIDIO, E.L. de. Adubação orgânica e mineral na cultura do melão num vertissolo do Submédio São Francisco. Pesquisa Agropecuária Brasileira. Brasília, DF. v.8, n.2, p.1191-1197, 1994.

GOLDBERG, D.; SHMUELI, M. Drip irrigation: A method used under drip and desert conditions of high water and soil salinity. Transactions of the ASAE, St. Joseph, v.13, n.1, p.38-41, 1970.

GORGATTI NETO, A.; GAYET J.P.; BEINROTN, E.W.; MATALLO, M.; GARCIA, E.E.C.; GARCIA, A.E.; ARDITO, G.F.G.; BORDIN, M.R. Melão para exportação: Procedimento de colheita e pós-colheita. Brasília: Embrapa-SPI/Frupex. 1994. 37p. Série Publicações Técnicas, 6.

LOPES, M.M. Caracteres descritivos e estimativas de parâmetros genéticos de cruzamento dialético parcial entre cinco cultivares de melão (Cucumis melo L.). Mossoró: ESAM. 1990. 45p. Tese Mestrado

PEREIRA, J.M. de A.; SOUZA, R.A. de. Mapeamento detalhado da área de Bebedouro - Petrolina, PE. Recife: SUDENE, 1967. $57 \mathrm{p}$.

PINTO, J.M.; SOARES, J.M.; CHOUDHURY,E.N.; PEREIRA, J.R. Adubação via água de irrigação na cultura do melão. Pesquisa Agropecuária Brasileira, Brasília, v.28, n.11, p.1.263-1.268, nov. 1993.

PINTO, J.M.; SOARES, J.M.; PEREIRA, J.R; CHOUDHURY,E.N.; CHOUDHURY, M.M. Efeitos de períodos e frequiências da fertirrigação nitrogenada na produção de melão. Pesquisa Agropecuária Brasileira. Brasília, v.29, n.9, p.1.345-1.350, set. 1994.

PINTO, J.M.; SOARES, J.M.; PEREIRA, J.R; COSTA, N.D.; BRITO, L.T. de L.; FARIA, C.M.B.; MACIEL, J.L. Sistema de cultivo de melão com aplicação de fertilizantes via água de irrigação. Petrolina, PE: Embrapa-CPATSA/Petrobrás. 1996. 24p. Circular Técnica, 36

PRABHAKAR, B.S.; SRINIVAS, K.; SHUKLA, V. Yield and quality of muskmelon (cv. Hara madhu) in relation to spacing and fertilization. Progressive Horticulture, v.17, n.1, p.51-55, 1985.

SOUZA, V.F. de. Freqüência de aplicação de $\mathrm{Ne} \mathrm{K}$ via irrigação por gotejamento no meloeiro (Cucumis melo L.), cv. Eldorado $300 \mathrm{em}$ solo de textura arenosa. Botucatu: UNESP-FCA, 1993. 131p. Tese Mestrado

SRINIVAS, K.; PRABHAKAR, B.S. Response of muskmelon (Cucumis melo L.) to varying levels of spacing and fertilizers. Singapore Journal of Primary Industries, Singapore, v.12, n.1, p.56-61, 1984.

SUAREZ, C.D.; RAMIREZ, C. Incidencia de la epoca de siembra en el comportamento de cuatro variedades de melon (Cucumis melo L.) em Azua, Republica Dominicana. Investigacion. v.9, n.1, p. 59-64, 1985. 